\title{
TOWARDS A CROATIAN 3D CADASTRE BASED ON THE LADM
}

\author{
N. Vučić ${ }^{\mathrm{a}}$, M. Mađer ${ }^{\mathrm{b}}$, M. Roićc ${ }^{\mathrm{c}}, \mathrm{S}$. Vranićd \\ ${ }^{a}$ State Geodetic Administration, Gruška 20, 10000 Zagreb, Croatia - nikola.vucic@dgu.hr \\ b DEMLAS project - Faculty of Geodesy, University of Zagreb, Kačićeva 26, 10000 Zagreb, Croatia - mmadjer@ gmail.com \\ ${ }^{c}$ Faculty of Geodesy, University of Zagreb, Kačićeva 26, 10000 Zagreb, Croatia-mroic@geof.hr \\ ${ }^{d}$ Faculty of Geodesy, University of Zagreb, Kačićeva 26, 10000 Zagreb, Croatia - svranic@geof.hr
}

KEY WORDS: 3D cadastre, LADM, 3D modelling, separate parts of real property, volume

\begin{abstract}
:
This paper presents a brief overview of the Land Administration Domain Model (ISO 19152 standard) and studies the development of the LADM national profile of the Republic of Croatia. Suggestions for better registration of separate parts of property as well as for 3D visualization of buildings and their separate parts (apartments, office spaces, etc.) are provided through use of case examples. A unique feature identifier of the separate parts of a property as well as volume registration of those separate parts is proposed as the preliminary basis for the Croatian 3D cadastre.
\end{abstract}

\section{INTRODUCTION}

The amount and the complexity of the information maintained according to the regulations of public authorities are constantly increasing (Mađer, 2012). That process is conditioned by the development of technologies and is occurring side by side with it. The list of possibilities that the new technologies provide is constantly increasing. Adopting technological accomplishments, especially in the area of information and communications technology, and their implementation in the system of registers, has enabled easier maintenance, access and exchange of information. That opened the possibility of collecting new, additional information that was not gathered earlier due to technical difficulties of maintenance. Cadastral data are basic data for land administration systems (Roić, 2012). Their availability in digital form makes them interesting to an increasing number of new areas of human activity and they become essential for their further development. Thus, this leads to a constant increase in the demand for cadastral information. Therefore, countries should work on the improvement of such information in order to keep abreast.

In the past 20 years the scientific community, engaged in the field of land information management, has more than ever focused on the development of an efficient 3D cadastral system. The necessity of the $3 \mathrm{D}$ cadastre establishment comes from (Stoter, 2004):

- The need for a complete register of 3D rights. The existing land administration systems based on a twodimensional approach are already registering rights related to 3D space. However, the 3D cadastre should explicitly register the $3 \mathrm{D}$ space to which those rights refer.

- The need for clear and easily accessible information in cases when the interests on the land overlap, whether it concerns overlapping ownership rights (e.g. building apartments) or in general in overlapping private rights with public law restrictions.

When we talk about completeness and consistency of the data, the information about objects which are not currently of primary importance to the cadastre but are of social interests (for example, public utility infrastructure) it would be much more effective to maintain them together with other cadastral information within one 3D cadastral system.

Based on these observations, it is necessary to implement these functionalities in the $3 \mathrm{D}$ cadastre:

- The possibility of registering rights that the rights holder has over a 3D space with the possibility of later access and interpretation of that information in a clear way;

- The possibility of establishing and maintaining links with other databases - their synergy effect will benefit the needs of society;

- The possibility of detecting and correcting errors in cadastral data based on the information of other databases.

The Croatian cadastral system is mostly $2 \mathrm{D}$, at best $2.5 \mathrm{D}$, but it has all predispositions to be 3D. It also has a real need to be 3D because the numerous demands by the users, but also the country itself as the owner of spatial data, increasingly reach into the third dimension. Since the Land Administration Domain Model (LADM) is also the ISO standard (ISO, 2012) and supports 3D registration of the real world situations, in this paper it is used as a foundation for a suggestion of how to establish a Croatian 3D cadastre.

\section{LAND ADMINISTRATION DOMAIN MODEL}

The LADM is an international standard developed by the Technical Committee ISO/TC 211 (geographic information and geomatics). The standard has the designation ISO 19152:2012 (Geographic information - Land Administration Domain Model) and has been available since 1 December 2012. To the experts from the field of land and land rights registration, the LADM gives an expandable basis for the development of an effective land administration system, but it also enables expansions and adaptation to local needs.

The LADM is an object model described by classes. The LADM core consists of four basic classes that describe the relations 
between persons and the objects of registration. Those classes are: LA_Party (Person), LA_BAUnit (Basic administrative unit) and LA_RRR (Right, Restriction and Responsibility). The objects of registration are spatial units determined by their spatial position (LA_SpatialUnit) (Figure 1).

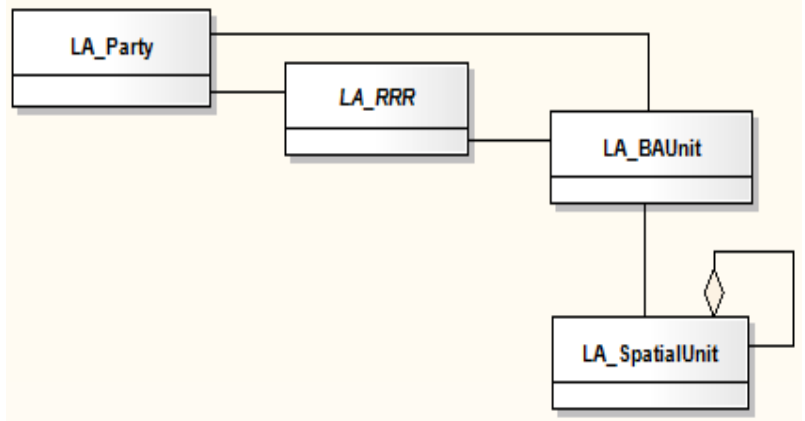

Figure 1. LADM core classes (ISO, 2012)

\subsection{Land Administration Domain Model packages}

The classes are organized in several packages which are designed so that they divide the LADM into meaningful groups. They can function separately and develop independently and maintain in a distributed surrounding in which the responsibility for each part of the system, presented by the package, lies within a separate organization. Thanks to the cooperation among all the responsible organizations it is possible for the system to function as an entity. This, naturally, refers to the cases when the responsibilities are divided among more organizations (Lemmen, 2012). In other cases, the use of the package is also desirable because it contributes to the clarity of the complex model.

The basic LADM packages are Party package, Administrative package, Spatial Unit package and Surveying and Representation subpackage. They contain the most important classes that describe the static part of the model, i.e. they define the way the system looks in a certain moment. For a complete, efficient and functional system its dynamic component is also important and has to be covered by the model. Special classes are focused on precisely that aspect of land administration domain modelling.
Therefore, the model supports the dynamic processes important for monitoring changes, storage and reconstruction of historical data state.

One of the basic and important assumptions of this model is its indisputable identification of any land feature on which the data is stored in some of the land administration systems, regardless of whether the feature still exists or is preserved in the system as a historical state. That is enabled by implementing special Oid value type. Oid is an abbreviation for object identifier. Formation of this value type is shown in the following figure (Figure 2).

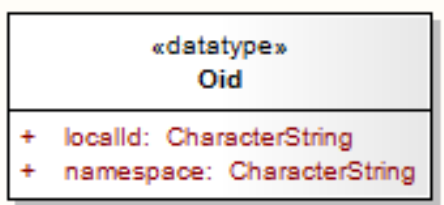

Figure 2. Definition of Oid value type (ISO, 2012)

Oid value type consists of two parts, a local identifier and a namespace. The data provider assigns the local identifier, which has to be unique within a certain namespace and can only contain capital and small Latin letters, numbers, underlines, full stops, commas and hyphens. Each namespace also has a unique identifier, i.e. a name which differentiates it from other namespaces. Namespaces are used for separating homonymic identifiers, i.e. identifiers that have the same shape, but different meaning (Kirasić, 2005).

2.1.1 Party package: The basic Party package class is LA_Party. This class refers to natural or non-natural persons for which the interests over land are registered within the land administration system. A non-natural person can be a company, municipality, agricultural community, church community, etc., and is represented by a director or other responsible person (Oosterom et al., 2009). As shown in figure 3, LA_Party class has one specialization in the form of LA_GroupParty class. It refers to any group of persons represented by the LA_Party class. Besides the mentioned specialization, there is an association class LA_PartyMember between those two classes.

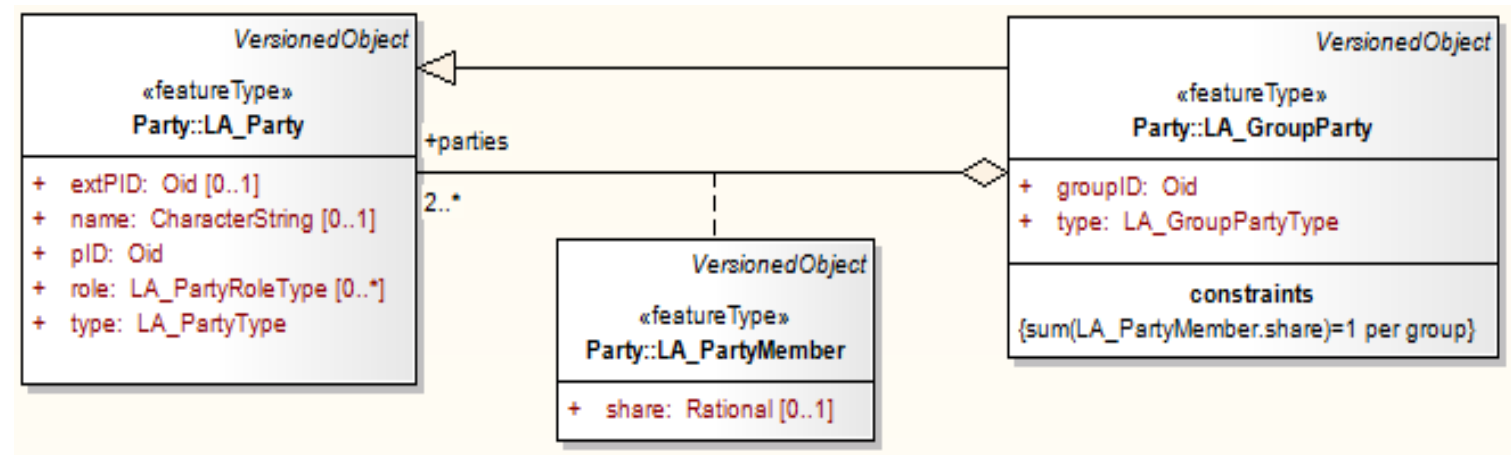

Figure 3. Party package classes (ISO, 2012) 


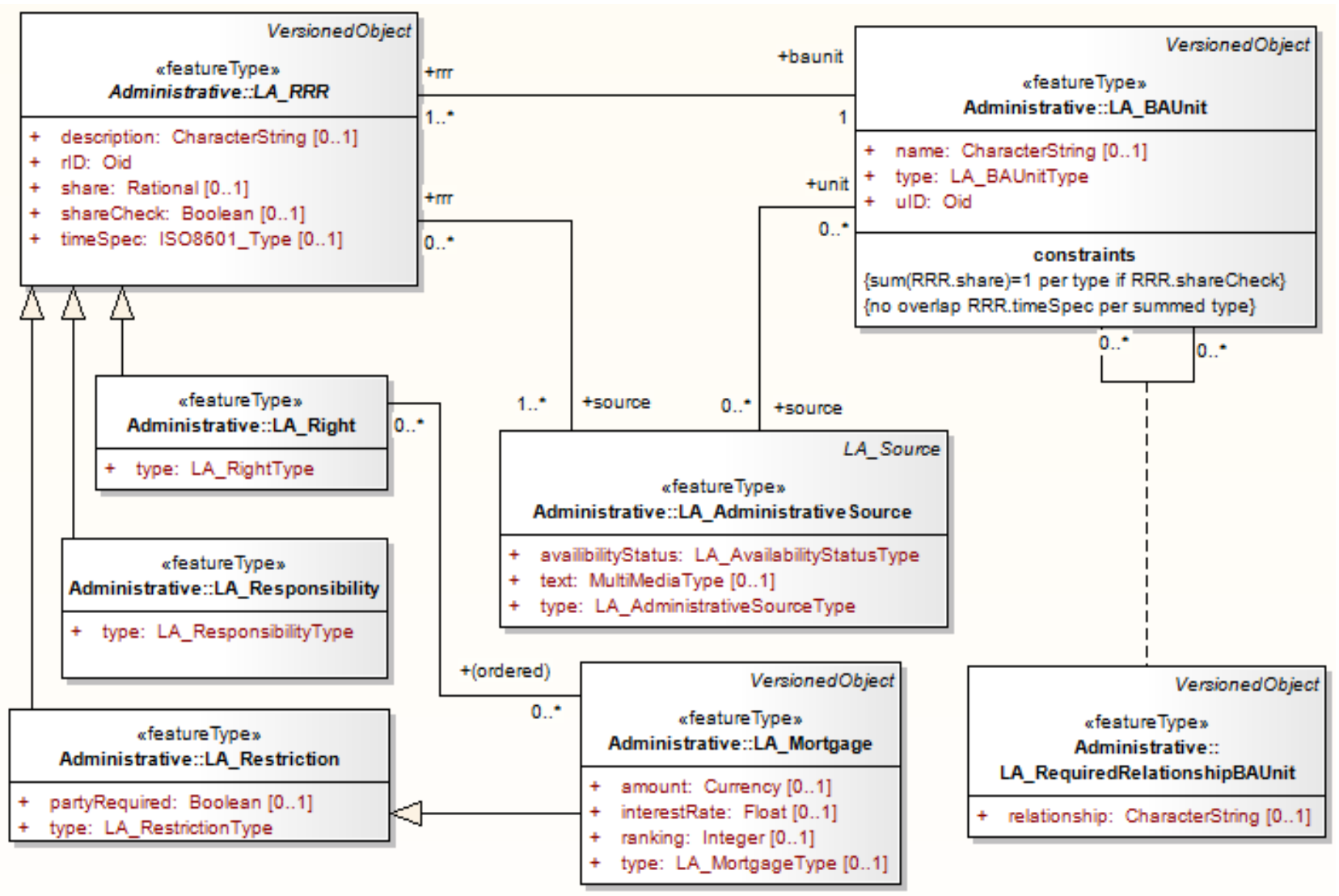

Figure 4. Administrative package classes (ISO, 2012)

It is optional, and provides the possibility of expressing shares in modelling of ownership, which includes groups of people presented by LA_GroupParty class. In such cases, when the model includes a group of people, it should be taken into account that the sum of all individual shares within a group should be 1 .

2.1.2 Administrative package: The basic Administrative package classes are LA_RRR and LA_BAUnit (Figure 4). LA_RRR is an abstract class which has three specializations. The first specialization is LA_Right, which refers to all the types of rights that can be achieved over the basic administrative units. The second specialization is LA_Restriction, which refers to the restrictions related to a basic administrative unit. Mortgage as a special type of restriction is modelled as a specialization of that class. The third specialization is LA_Responsibility class, which refers to the responsibilities that the rights holder has to obey on a basic administrative unit. All registrations of rights, restrictions and responsibilities over the basic administrative units are made based on official documentation, and for those the LA_AdministrativeSource class is provided (Lemmen et al. 2010a).

The basic administrative unit, described by LA_BAUnit class, mostly consists of one or more spatial units, but the model also allows a special case where the existence of a basic administrative unit is possible without knowing the spatial unit that spatially determines it. Thanks to this, it is possible to register land rights in land administration systems which are based on deed registration where the land, i.e. the spatial unit, is not precisely spatially determined (for example, "Tapija" system). The precondition which every basic administrative unit has to fulfil regardless of the amount of spatial units it comprises, is that the rights on it, as well as restrictions and responsibilities, are unique and homogenous. The term "unique" implies the same person or the same group of persons as the holders of rights, restrictions and responsibilities over the whole basic administrative unit, and the term "homogenous" implies the existence of identical rights, restrictions and responsibilities over the whole basic administrative unit.

In the case of absence of some spatial units necessary for precise spatial determination of basic administrative units, the model is providing the association class LA_RequiredRelationshipBAUnit whose purpose is to descriptively define its spatial layout.

2.1.3 Spatial Unit package: The basic Spatial Unit package class is the LA_SpatialUnit (Figure 5). The model supports the usual 2D and 3D spatial unit representations, but it also supports the spatial units representations by using one point or a combination of the above mentioned. This package enables the grouping of spatial units in two ways. The first includes LA_SpatialUnitGroup class, which groups any number of the existing spatial units by making a new and more spacious unit (for example, grouping cadastral parcels into a cadastral municipality). The second includes grouping, i.e. connecting parts of a certain spatial unit into one entity. This is achieved with the help of an aggregation association of LA_SpatialUnit classes onto itself. This enables the recognition 


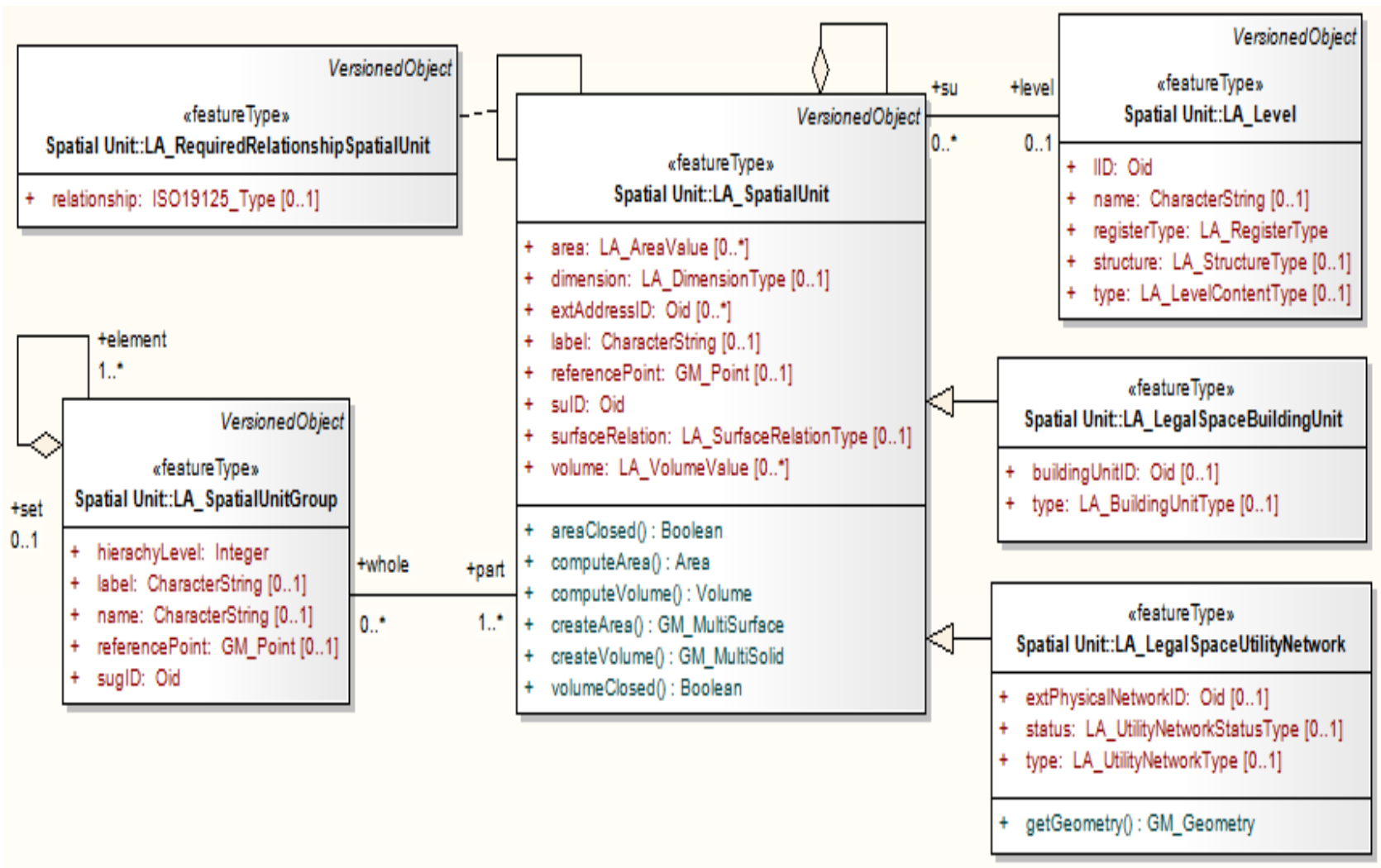

Figure 5. Spatial unit package classes (ISO, 2012)

of basic administrative units on which the system gathers and maintains the data (for example, the cadastral parcels), but also the recognition of their parts (for example, the parts of cadastral parcels, so-called land parcels of unique land usage, which are spatially determined and we can also consider them spatial units). The basic difference between these two ways of grouping is that in the second there is a direct association with LA_BAUnit class while in the first that is not the case (Lemmen et al., 2010b).

LA_SpatialUnit class has two specializations. The first is LA_LegalSpaceBuildingUnit and is designed for buildings while the other specialization is LA_LegalSpaceUtilityNetwork, which is designed for utilities.

LA_RequiredRelationshipSpatialUnit class, is designed for cases when geometry data of spatial units are not sufficiently accurate to provide reliable results while running the computer spatial operations (for example, a building, which is in reality completely within the boundaries of a certain cadastral parcel, but due to inaccurate spatial data partially falls outside of it). In that case, the accurate connections between certain spatial units are determined with the help of the mentioned class. The connections determined in such a way between spatial units have a priority, i.e. they overpower the connections determined by the computer's spatial operations. The model also offers the possibility of organizing the spatial units via the LA_Level class. It is possible to organize the spatial units in several levels regarding their common spatial, topological or semantic features.

2.1.4 Surveying and Representation package: The Surveying and Representation package contains four classes (Figure 6) LA_Point class is provided for points. They belong to the group of basic geometrical primitives. Unlike all the other classes from that package, points are dimensionless, which makes them the most suitable for the representation of position and shapes of various land features in land administration systems. The position of the point in a certain coordinate system is determined by its coordinates. There are various techniques of determining point coordinates. Some of the most significant techniques are classic field methods; observations by global navigation satellite systems (GNSS), aero-photogrammetry and others. Every measurement, i.e. every determination of coordinates, is in some way documented. Whether it is the measuring record stored in an instrument, photogrammetric image or the measuring sketch, all those documents are considered to be an integral part of a land administration system so the LADM provided for them is the LA_SpatialSource class.

The classes LA_BoundaryFaceString and LA_BoundaryFace are for $2 \mathrm{D}$ and $3 \mathrm{D}$ representation of spatial units (Oosterom et al. 2011). 


\begin{tabular}{|c|c|c|c|c|c|c|c|c|}
\hline \multirow{2}{*}{\multicolumn{3}{|c|}{$\begin{array}{c}\text { VersionedObject } \\
\text { seature Typew } \\
\text { Surveying and Representation::LA_BoundaryFace String }\end{array}$}} & \multicolumn{2}{|r|}{ +source } & \multicolumn{4}{|c|}{ LA_Source } \\
\hline & & & $0 .$. & $0 . .1$ & \multirow{2}{*}{\multicolumn{4}{|c|}{$\begin{array}{l}\text { «festure Types } \\
\text { Surveying and Representation:: } \\
\text { LA_SpatialSource }\end{array}$}} \\
\hline \multirow{2}{*}{\multicolumn{3}{|c|}{$\begin{array}{l}\text { + bfsID: Oid } \\
\text { + geometry: GM_MultiCurve [0..1] } \\
\text { + locationByText: CharacterString [0..1] }\end{array}$}} & & & & & & \\
\hline & & & & & \multicolumn{4}{|c|}{$\begin{array}{l}+ \text { measurements: OM_Observation }\left[0 . .{ }^{*}\right] \\
+ \text { procedure: OM_Process }[0 . .1] \\
+ \text { type: LA_SpatislSourceType }\end{array}$} \\
\hline \multicolumn{3}{|c|}{$\begin{array}{c}\text { constraints } \\
\left\{\text { either geometry }\left(2 . .^{*} \text { points }\right) \text { or locationByText (0 points)\} }\right.\end{array}$} & & & \multirow[t]{3}{*}{ tsource } & \multirow[t]{4}{*}{$1 . . *$} & \multirow[t]{4}{*}{ +source } & \multirow[t]{2}{*}{$0 . .1$} \\
\hline $\begin{array}{l}0,2 .{ }^{*} \\
\text { \{ordered\} }\end{array}$ & \multicolumn{2}{|l|}{$0 .{ }^{*}$} & & & & & & \\
\hline \multirow{2}{*}{\multicolumn{2}{|c|}{$\begin{array}{c}\text { VersionedObject } \\
\text { sfestureType» } \\
\text { Surveying and Representation::LA_Point }\end{array}$}} & \multicolumn{2}{|c|}{ tsource Point } & & & & & \multirow[b]{2}{*}{$0 .{ }^{*}$} \\
\hline & & \multirow{2}{*}{\multicolumn{2}{|c|}{$1 .}}$. & & & & & \\
\hline \multirow{3}{*}{\multicolumn{2}{|c|}{$\begin{array}{l}\text { + estimatedAccuracy: Length } \\
\text { + interpolationRole: LA_InterpolationType } \\
\text { + monumentation: LA_MonumentationType [0..1] } \\
\text { + originalLocation: GM_Point } \\
\text { + pID: Oid } \\
\text { + pointType: LA_PointType } \\
\text { + productionMethod: LI_Lineage [0..1] } \\
+ \text { transAndResult: LA_Transformation [0..*] }\end{array}$}} & & & \multirow{2}{*}{\multicolumn{5}{|c|}{$\begin{array}{c}\text { VersionedObject } \\
\text { «festure Type» } \\
\text { Surveying and Representation::LA_BoundaryFace }\end{array}$}} \\
\hline & & \multirow{3}{*}{\multicolumn{2}{|c|}{$\begin{array}{ll}0,3 . .^{*} & 0 . .^{*} \\
\text { \{ordered\} }\end{array}$}} & & & & & \\
\hline & & & & \multicolumn{5}{|c|}{$\begin{array}{l}\text { + } \text { bf|D: Oid } \\
\text { + geometry: GM_MultiSurface [0..1] } \\
\text { + locationByText: CharaterString [0..1] }\end{array}$} \\
\hline \multicolumn{2}{|c|}{ + GetTransResult0: GM_Point } & & & \multicolumn{5}{|c|}{ 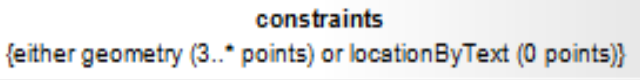 } \\
\hline
\end{tabular}

Figure 6. Surveying and Representation package classes (ISO, 2012)

2.1.5 Special Classes package: Along with the packages and classes mentioned in the previous chapters, the LADM contains a special package with VersionedObject and LA_Source classes. The majority of the classes described in the previous sections are their specializations. As the LADM supports certain dynamic processes it is important to ensure attributes that will enable monitoring these processes. Those attributes are contained in VersionedObject class. To certain parts of classes the VersionedObject class expands the definition by additional attributes, which enables temporally defining the objects. That is necessary for monitoring changes, storage and reconstruction of historical state of data. LA_Source is a parent class to the earlier mentioned LA_AdministrativeSource and LA_SpatialSource classes, which describe official documentation and various spatial documents made during the survey and observation, based on which the registration of rights, restrictions and responsibilities and accompanying spatial changes in data are carried out. LA_Source class gives these two classes common attributes which help to temporally define certain phases in carrying out the mentioned changes.

\section{3D CADASTRE BASED ON LADM}

The traditional concept of a cadastral parcel as a part of the land on which the rights are homogenous (in a two-dimensional sense) in the LADM is expanded by adding a third dimension which enables spatial representations of situations in which the interests over land overlap (Stoter et al., 2013). In addition, apart from using topologically structured cadastral parcels for the representation of a person's interests over land, it enables some other approach, based on textual descriptions, sketches, nonstructured lines, etc., to enable functioning of the system in situations when the data are not complete or when there is no possibility of establishing a more quality system.

Still, as the basic concept for the 2D representation of the spatial units, the LADM implies vertical boundary face strings, which spread infinitely, and are laid within the boundaries of spatial units (Figure 7), while for 3D representations of spatial units it implies boundary faces, but neither infinite, nor necessarily vertical, but aligned so that they close a certain 3D space. Precisely because of that it is possible to interpret a $2 \mathrm{D}$ representation as a 3D prismatic volume without the upper and lower boundary. By interpreting 2D and 3D representations in such a way, they can be fitted into the same data model (Stoter, 2004).

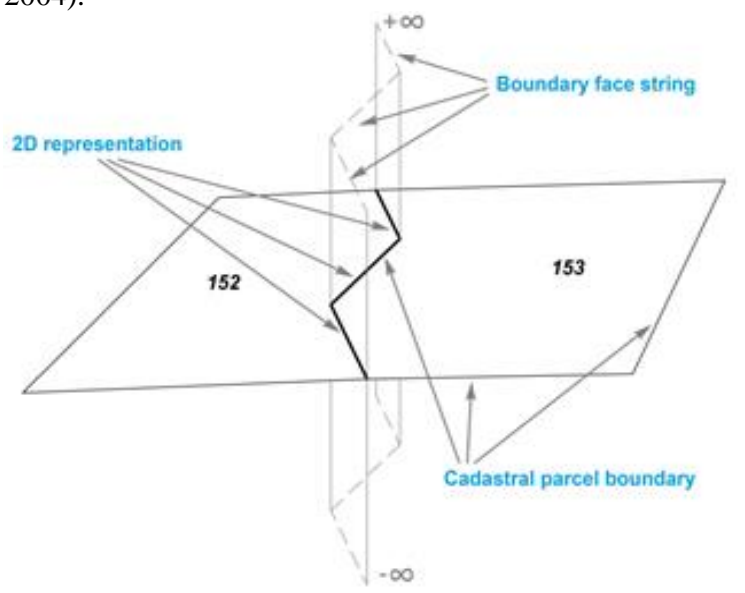

Figure 7. The concept of vertical boundary face strings (ISO, 2012) 
Liminal spatial units represent a special case in such a data model when a $2 \mathrm{D}$ representation of one spatial unit is right next to a $3 \mathrm{D}$ representation of its neighbouring spatial unit (Figure 8). On the contact points of $2 \mathrm{D}$ and $3 \mathrm{D}$ representations there is an overlap of infinite vertical face string, which serves as a $2 \mathrm{D}$ representation, and a vertical face, which is used to model a side of a 3D spatial unit. This kind of overlap is not permitted because it represents redundancy in the model. The existence of these two faces in a common model is conditioned by their merger in a common infinite vertical face string, split in a way that one of its parts matches the face by which is modelled the 3D side of a spatial unit, while as an entity, it meets the needs of 2D representation of a liminal spatial unit.

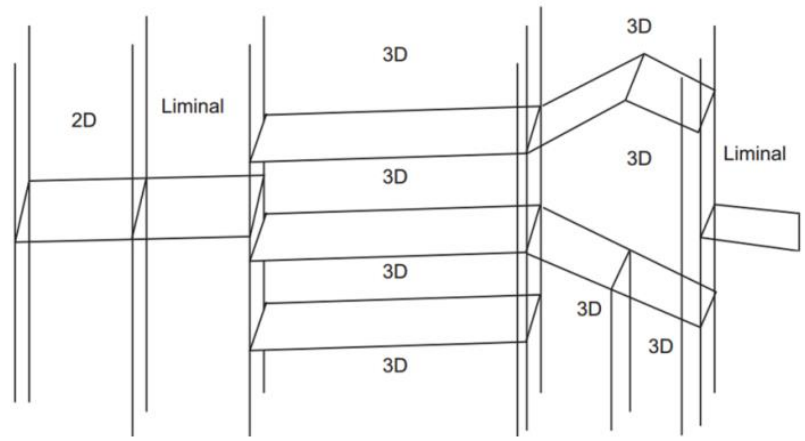

Figure 8. Mixed 2D/3D representation (ISO, 2012)

In the LADM, 2D and 3D data are treated in a consistent manner throughout the model. It is important to realise that there is a difference between the 3D physical object itself and the legal space related to this object. The LADM concerns only legal space which is relevant for land administration. That legal space can, but does not have to, correspond with the physical object, and most often it does not have a physical manifestation (for example, the safety zone around a tunnel as a legal space in relation to the tunnel itself as a physical object) (Döner et al., 2010).

\subsection{Croatian national LADM profile}

The first version of the Croatian national LADM profile was developed in 2012 (Vučić et al., 2013b). The profile is made as an extension of the basic LADM model by new classes. These are mostly derived as specializations of original LADM classes, and in the model, it can be recognized based on the prefix "HR" in their names (Figure 9). In the mentioned classes new value types defined by appropriate code lists are used (Figure 10).

In 2013 additional research was undertaken (Vučić et al., 2013a) which answered some key questions:

- What are the user's demands of the Croatian land administration system?

- Which LADM classes can be directly applied to the Croatian land administration system?

- Which LADM classes can be altered to be suitable for Croatian land administration system?

- How to design a Croatian land administration system to meet the needs of the LADM standard?

\subsection{Registering separate parts of a real property}

Buildings and other structures are registered in the cadastre with the following attributes: area, intended building use, building name and house number. A Land book receives 2D data concerning real property from the cadastre. Real property may be further divided into common and separate parts and registered in the Land book based on the report on partition of real property. In that way, the co-owners of a real property stay in the co-owner relationship on common parts, and each of them becomes an individual owner of a separate part (for example, an apartment or an office space). Such a way of registering separate parts began in 1996, and for the majority of the real property the partition has not yet been implemented.

According to the Regulation of connecting the Land book and the book of deposited contracts (Official Gazette, 2010a), the legal obligation of the building manager is to start the procedure of connecting the Land book with the Book of deposited contracts. The regulation was implemented because it had been noticed that many buildings built several decades ago have not been registered in the cadastre or the Land book, and they have not been partitioned. According to the mentioned regulation, the description of the separate part of a real property contains the data on intended use (office space, apartment and other), number of rooms, position of separate parts in a building and the surface of the separate part (for example, two-bedroom apartment on the first floor, right side, with the usable area of $52 \mathrm{~m}^{2}$ ). With the description of the separate parts of a real property the additions are also mentioned (a woodshed, a garage, a parking space, a balcony, a garden, a terrace and similar), along with their area, if there is such data. Buildings are registered in the cadastre at the obligatory request of a party. A geodetic report prepared by the authorized surveying company must be supplied with this request. The responsible cadastral office must prior review and certify the report. Since 2007 the cadastral offices have partially participated in the control of the legality of the construction of various buildings. As the condition for registering buildings into a cadastre, and then taking over that data into Land book, what needed to be presented along with the geodetic reports was the right documentation based on which the building could have been built (Official Gazette, 2007). The partitioned real properties can also be registered in the non-technical part of the cadastral documentation.

\subsection{The current 3D products that are used in the cadastre}

A special geodetic map report implies a digital ortho-photo map with elevation display - contour lines and altitudes with embedded cadastral map or topographical map with embedded cadastral map, all to the appropriate scale and certified by the competent authority for state surveying and real property cadastre. A special geodetic map report was used in cadastral offices until 01/01/2014 when package of new laws in the field of Construction and Spatial Planning came into force (Building Act, Spatial Planning Act and Building Inspection Act issued by Croatian Parliament on 06/12/2013). Based on the Spatial Planning Act, the Regulation on Geodetic Project was enacted and according to it the document called Geodetic Situational Draft became its integral part. This situational draft is made to display position and elevation data on all visible natural and built features of the land surface (Figure 11) in the construction area (e.g. buildings and other structures, utility lines with associated facilities, traffic infrastructure, vegetation, water and related objects, relief etc.) (Official Gazette, 2014). 


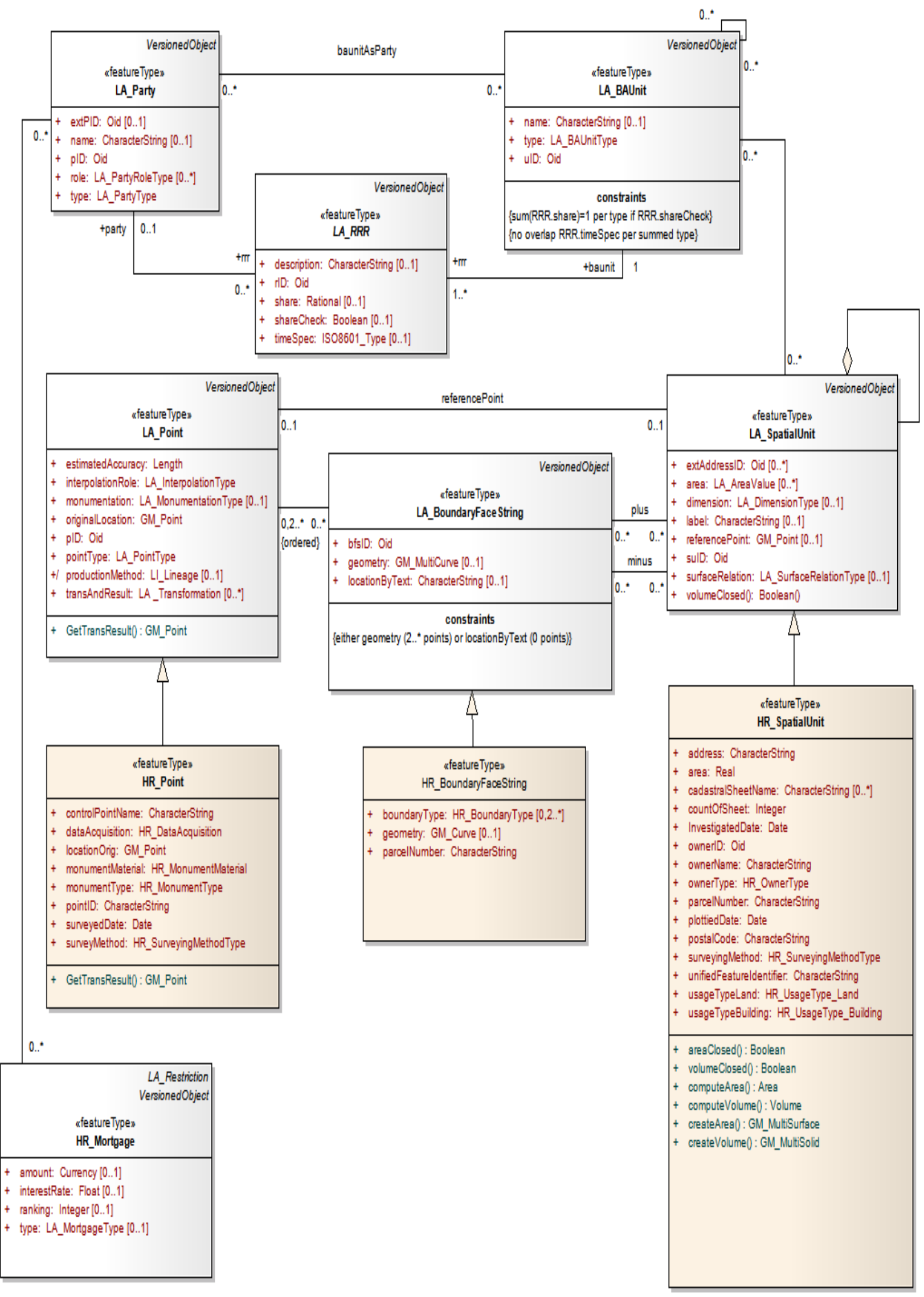

Figure 9. LADM profile Croatia

This contribution has been peer-reviewed. The double-blind peer-review was conducted on the basis of the full paper. https://doi.org/10.5194/isprs-annals-IV-4-W4-399-2017 | @ Authors 2017. CC BY 4.0 License. 


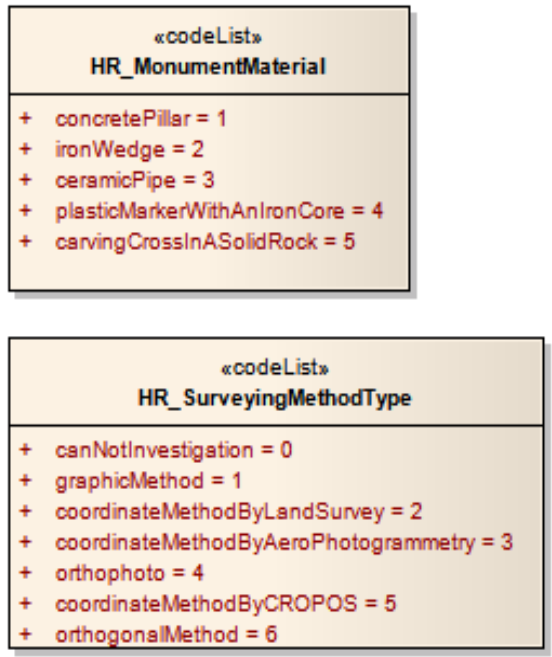

\begin{tabular}{|l|}
\hline HR_DataAcquisition \\
\hline$+\quad$ mapDigitizing $=1$ \\
$+\quad$ surveyed $=2$ \\
\hline
\end{tabular}

\begin{tabular}{|c|}
\hline $\begin{array}{c}\text { «codeList: } \\
\text { HR_BoundaryType }\end{array}$ \\
\hline $\begin{array}{l}+ \text { boundaryOfUsage Type }=1 \\
+ \text { boundaryOfParcel }=2 \\
+ \text { boundaryOfCadastralMunicipality }=3 \\
+ \text { boundaryOfCommunityOrTown }=4 \\
+ \text { boundaryOfCounty }=5 \\
+ \text { boundaryOfState }=6\end{array}$ \\
\hline
\end{tabular}

\begin{tabular}{|c|}
\hline $\begin{array}{c}\text { «codeList* } \\
\text { HR_ResponsibilityType }\end{array}$ \\
\hline $\begin{array}{l}+ \text { monumentMaintenance }=1 \\
+ \text { waterwayMaintenance }=2 \\
+ \text { snowRemoval }=3 \\
+ \text { icicleRemoval }=4\end{array}$ \\
\hline
\end{tabular}

\begin{tabular}{|c|}
\hline $\begin{array}{l}\text { «codeList» } \\
\text { HR_OwnerType }\end{array}$ \\
\hline $\begin{array}{l}+ \text { owner }=1 \\
+ \text { possessor }=2 \\
+ \text { unregisteredOwner }=3\end{array}$ \\
\hline
\end{tabular}

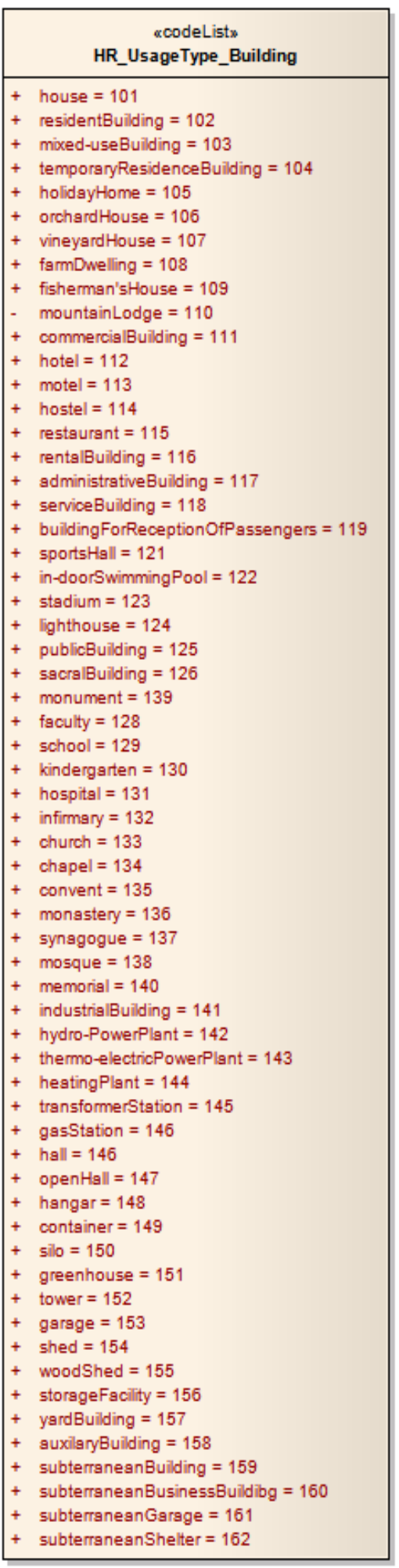

\begin{tabular}{|c|}
\hline $\begin{array}{c}\text { «codeList: } \\
\text { HR_UsageType_Land }\end{array}$ \\
\hline 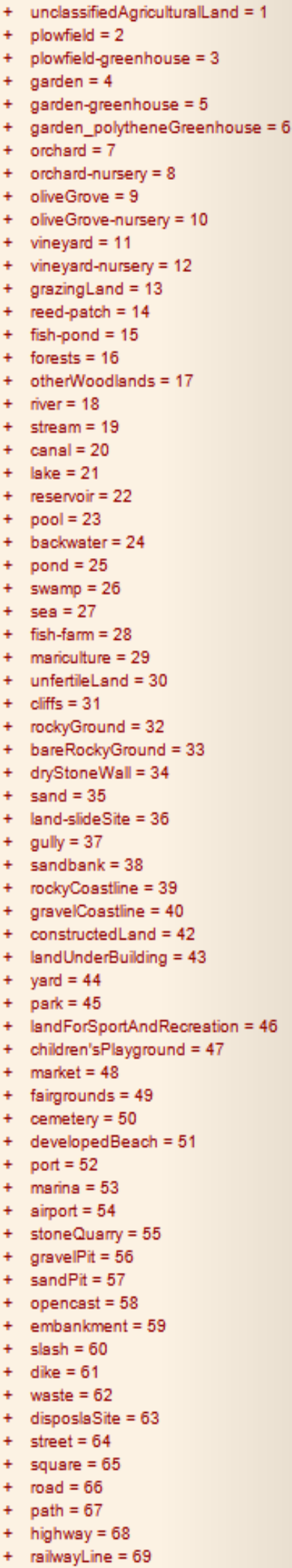 \\
\hline
\end{tabular}

Figure 10. LADM profile Croatia (code lists) 


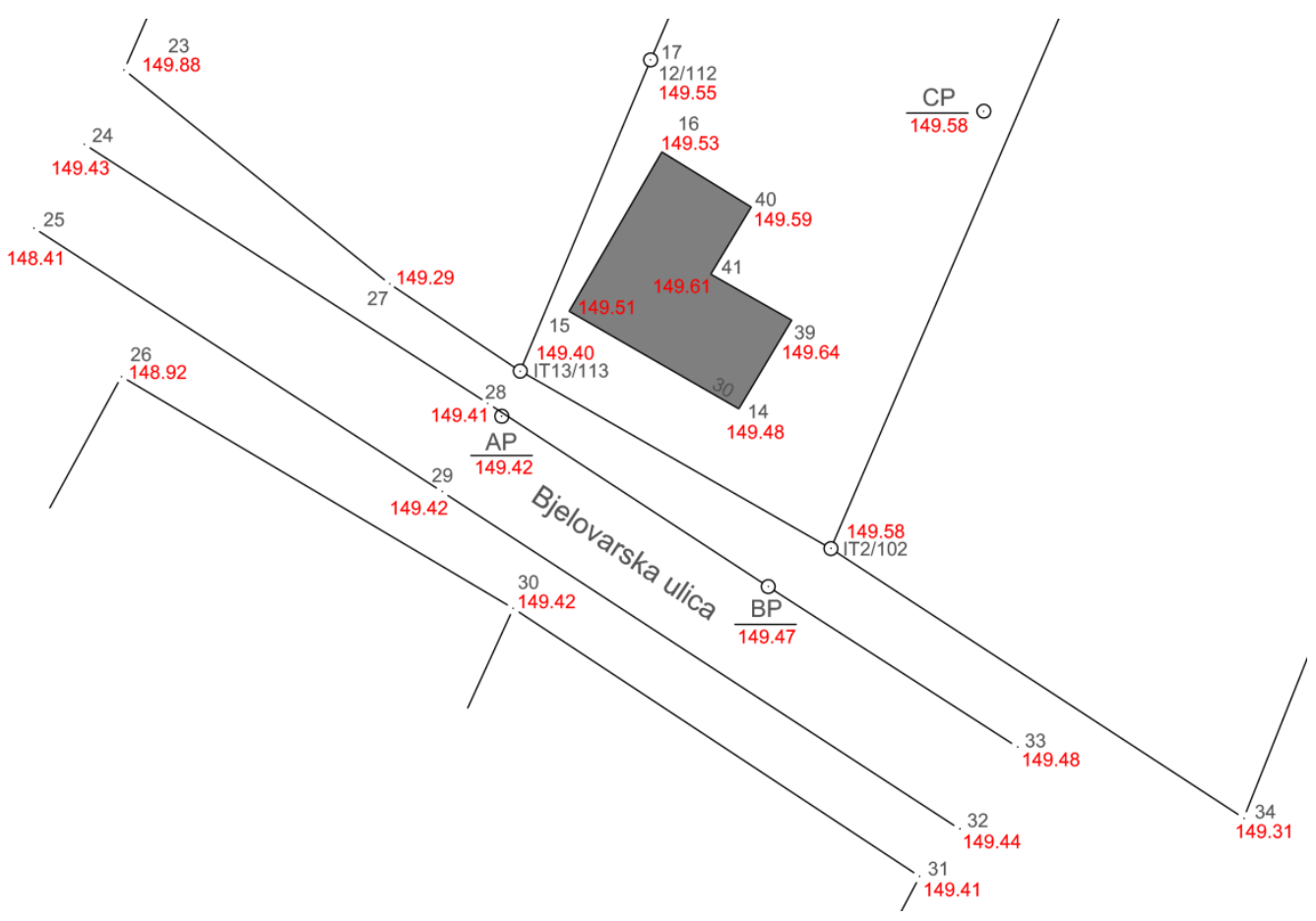

Figure 11. Geodetic situational draft - a part (URL 1)

The utility cadastre is established and managed in the Republic of Croatia by the Law on State Survey and Real Property Cadastre (Official Gazette, 2007) and passed to local administration. A few local administrations have taken that responsibility, and for all the others, utility cadastre reports are verified and archived in cadastral offices. The most important component of registering utilities in the cadastre is their spatial position; hence, for that purpose utilities are measured by geodetic methods, which means surveying in a way that positional and altitude data are collected. In addition, when measuring utilities, they measure surrounding land features (pillars, manholes, canals, leaks and others). It is necessary to measure all the objects that belong to that utility line. A utility survey is conducted when the utility line is open, and for surveying of already existing and non-registered utility lines the visible exterior utility line parts are used.

Three years ago a practice of making geodetic projects was introduced for the construction and spatial planning as well as for preparation of utility cadastre reports (public utility infrastructure) which requires the use of technical specifications for determining $3 \mathrm{D}$ coordinates in a coordinate system of the Republic of Croatia. These specifications prescribe the correct ways of measuring and recording coordinates in an analogue and digital form for cadastral purpose (land, real property and utility cadastre) as well as detailed topographic surveying, preparation of geodetic maps and all other georeferenced representations.

\section{THE DEVELOPMENT OF 3D CADASTRE}

In the process of establishing a complete 3D cadastre the important step is to register all buildings and structures (especially bridges, tunnels, overpasses, underpasses, traffic infrastructure, underground buildings, etc.) as well as underground and overground public utility infrastructure. It is especially important to register buildings in $3 \mathrm{D}$ form and adequately describe their separate parts. 3D building models suitable for implementation in a complete $3 \mathrm{D}$ cadastre can be made out of 2D geodetic data (mostly geodetic reports) or out of plans for separate parts of the buildings. With the purpose of a complete 3D cadastre, the data on the actual height of the separate part must accompany that information. If there is no such data, and we are talking about buildings where separate parts are repeated on a certain standard height, with the purpose of completeness of 3D cadastre a less strict approach can be used. For 3D modelling and later visualization what can be used is the standard partition height (for example, $2.60 \mathrm{~m}$ or $2.80 \mathrm{~m}$ ) and accompanying metadata on the source of information on height. Data modelled in such a way can be combined with other data (for example, digital cadastral map, non-technical part of the cadastral documentation, geoportal or the currently free services such as Google Earth, Google Street View and others).

\subsection{D building modelling}

Today's computer technologies enable advanced methods of real property registration in official registers (for example, cadastre or 3D city models in those countries where they exist as official registers). There is also the possibility of connecting to services which visualize 3D space such as Google Earth, Google Street View, CityGML and other advanced and worldwide publicly accessible technologies. 3D building representations can be quality made out of the building plans that were used for registering special building parts.

Separate parts of a real property can be modelled as integral parts of a 3D building model (

Figure 12) and during that process a unique identifier of separate parts of a real property can be assigned to an apartment or an office space within each building (Vučić et al., 2013c). Attributes which can be registered for separate parts of a real property, and can be potentially important, are 3D coordinates, plan area and volume (which are calculated by $3 \mathrm{D}$ coordinates), orientation of separate parts of a real property, the use (for example, an apartment, suite, office space, etc.), the number of floors in a 
building, the year in which the building was built, etc. That means everything that is necessary for the country as the founder and owner of the official register, having in mind the needs of potential users of that register, the needs of the country itself and the economic progress and legal security which is expected from the official real property register.

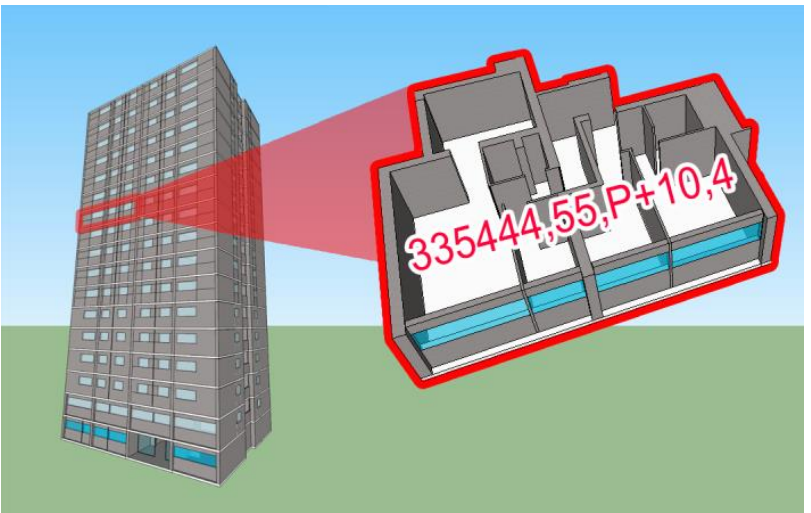

Figure 12. Special real property part - an apartment

The unique feature identifier can be assembled by using the identification number of the municipality, the number of a building in a cadastral municipality, floor (where underground partitions are identified as $\mathrm{P}-1$ until $\mathrm{P}-\mathrm{n}$, ground floor as $\mathrm{P}$, and overground partitions as $\mathrm{P}+1$ until $\mathrm{P}+\mathrm{n}$ ) and finally the number of the separate part of a real property on an individual floor. As an example, a building was chosen in Zagreb, Trnsko 12, an apartment on the $10^{\text {th }}$ floor (Table 1). For registering other buildings such as tunnels, bridges, viaducts, etc., which are modelled in 2D cadastre by a topographical symbol on a cadastral plan, other similar principles can be used.

\begin{tabular}{|l|l|l|l|}
\hline $\begin{array}{l}\text { Identification } \\
\text { number of a } \\
\text { cadastral } \\
\text { municipality }\end{array}$ & $\begin{array}{l}\text { Number of a } \\
\text { building or } \\
\text { another } \\
\text { construction in } \\
\text { a cadastral } \\
\text { municipality }\end{array}$ & Floor & $\begin{array}{l}\text { Number of a } \\
\text { separate } \\
\text { part of real } \\
\text { property }\end{array}$ \\
\hline 335444 & 55 & $\mathrm{P}+10$ & 4 \\
\hline Unique feature identifier $=335444,55, \mathrm{P}+10,4$ \\
\hline
\end{tabular}

Table 1. An example of forming a unique identifier of a separate part of real property

\subsection{Volume of special real property parts}

The volume of separate parts of a real property can serve as a transition solution until the establishment of a complete 3D cadastre. The Croatian land administration system has not yet provided for registering the volume of apartments and office spaces. However, in the last 6 years, a cadastre actively participates in the control of the legality of the building construction from a $2 \mathrm{D}$ aspect. The next step in the transition from $2 \mathrm{D}$ to $3 \mathrm{D}$ cadastre should be the implementation of the volume data of apartments and office spaces in the existing 2D cadastral database. The basis for the calculation of volume data of separate parts of a real property already exists in the form of Regulation on the method of calculating area and volume in the building projects (Official Gazette, 2010b).

\section{CONCLUSION}

Croatia has the possibility to develop and use the 3D cadastral system because it has a well-developed 2D cadastral system. Three-dimensional use of land (construction of multi-floor buildings, construction of bridges, tunnels, viaducts, construction of public utility infrastructure over and underground) is continually growing so the establishment of a $3 \mathrm{D}$ cadastre is highly necessary for better registration of ownership, legal security in the real property market for better land and building management. For the development of a 3D cadastral system of any country, including Croatia, a good foundation is the LADM, which in its core provides registering 3D situations from the real world and so can be applied in the development of new 3D cadastral systems, but also in the transition from existing $2 \mathrm{D}$ and $2.5 \mathrm{D}$ cadastral systems into 3D cadastral systems.

The Croatian LADM national profile supports situations from the real world which are basic for the $3 \mathrm{D}$ cadastre; however, for the establishment of the complete 3D cadastre it is necessary to first harmonize and adapt the existing regulations and to better regulate registration of separate parts of real property in the cadastre as the basic real property register.

Along with publicly available services such as Google Earth and Google Street View and others, which for some time now deal with spatial modelling and free provision of these data to users, there is also the need for an official register. As a private foreign company Google can always withhold the data or charge a fee. Also, for its need the country must have higher reliability of data and cannot fully depend on the above mentioned products. Hence, it has to develop its own 3D data register based on welldefined regulations which will guarantee the legal security of registered facts and meet the technical preconditions for a $3 \mathrm{D}$ cadastre.

\section{ACKNOWLEDGEMENTS}

This work has been fully supported by Croatian Science Foundation under the project HRZZ-IP-11-2013-7714. 


\section{REFERENCES}

State Geodetic Administration (2013): Technical Specifications for Determining Coordinates of Points in the Coordinate System of the Republic of Croatia.

ISO (2012): Geographic information - Land Administration Domain Model (LADM) - ISO 19152. International Organization for Standardization, Switzerland.

Döner, F., Thompson, R., Stoter, J., Lemmen, C., Ploeger, H., Oosterom, P. van, Zlatanova, S. (2010): 4D cadastres: First analysis of legal, organizational, and technical impact - With a case study on utility networks. Land Use Policy, 27, str. 10681081 .

Kirasić, D. (2005): XML tehnologija i primjena u sustavima procesne informatike, in Croatian, Proceedings of the 28th International Convention MIPRO 2005 - Rijeka: Croatian Society for Information and Communciation Technology, Electronics and Microelectronics - MIPRO, str. 79-88, Opatija, Croatia.

Lemmen, C. (2012): A Domain Model for Land Administration. Disertacija, TU Delft, Netherlands.

Lemmen, C., Oosterom, P. van, Eisenhut, C., Uitermark, H. (2010a): The Modelling of Rights, Restrictions and Responsibilities (RRR) in the Land Administration Domain Model (LADM). Proceedings of the XXIV FIG International Congress 2010, April 2010, Sydney, Australia.

Lemmen, C., Oosterom, P. van, Thompson, R., Hespanha, J., Uitermark, H. (2010b): The Modelling of Spatial Units (Parcels) in the Land Administration Domain Model (LADM). Proceedings of the XXIV FIG International Congress 2010, April 2010, Sydney.

Mađer, M. (2012): Model of linking cadastre with related registers. Disertation, University of Zagreb, Faculty of Geodesy

Official Gazette (2007): Law on State Survey and Real Property Cadastre, 16

Official Gazette (2010a): Regulation of connecting Land book and the Book of deposited contracts, 60

Official Gazette (2010b): Ordinance on the method of calculating surface and volume in building projects, 90

Official Gazette (2014): Ordinance on surveying design, 56.

Oosterom, P. van, Groothedde, A., Lemmen, C., Molen, P. van der, Uitermark, H. (2009): Land Administration as a Cornerstone in the Global Spatial Information Infrastructure. International Journal of Spatial Data Infrastructures Research, 4.

Oosterom, P. van, Lemmen, C., Uitermark, H., Boekelo, G., Verkuijl, G. (2011): Land Administration Standardization with focus on Surveying and Spatial Representations. Proceedings of the ACMS Annual Conference Survey Summit 2011, San Diego.

Roić, M. (2012): Upravljanje zemljišnim informacijama Katastar. in Croatian, University of Zagreb, Faculty of Geodesy, Zagreb.
Stoter, J. (2004): 3D Cadastre. Disertacija, Netherlands Geodetic Commission, Publications on Geodesy, 57, Netherlands.

Stoter, J., Ploeger, H., Oosterom, P. van (2013): 3D cadastre in the Netherlands: Developments and international applicability. Computers, Environment and Urban Systems, 40, str. 56-67.

Vučić, N., Markovinović, D., Mičević, B. (2013a): LADM in the Republic of Croatia - Making and Testing Country Profile. LADM 2013 workshop, Kuala Lumpur, Malaysia.

Vučić, N., Roić, M., Kapović, Z. (2013b): Examination of Compatibility Between the Croatian Land Administration System and LADM. Developments in Multidimensional Spatial Data Models, Lecture Notes in Geoinformation and Cartography, str. 155-171, Springer, Berlin, Germany.

Vučić, N., Tomić, H., Roić, M. (2013c): Registration of 3D Situations in Croatian Land Administration System. ISG 2013 symposium, Kuala Lumpur, Malaysia.

URL 1: State Geodetic Administration, http://www.dgu.hr/assets/uploads/Dokumenti/Novosti/Geodetsk i\%20projekt/Geodetski_projekt_primjer_2.pdf, page acces June, June $1^{\text {st }}, .2017$. 